\title{
Thermal etching of silver: Influence of rolling defects
}

\author{
M. Ollivier ${ }^{\mathrm{a}, *}$, R.M. Harker ${ }^{\mathrm{b}}$, R.J. Chater ${ }^{\mathrm{a}}$, C.M. Gourlay ${ }^{\mathrm{a}}$ \\ ${ }^{a}$ Department of Materials, Imperial College London, SW7 2AZ, UK \\ ${ }^{b} A W E$ Aldermaston, Aldermaston, Reading, RG7 $4 P R, U K$
}

\begin{abstract}
Silver is well known to be thermally etched in an oxygen-rich atmosphere and has been extensively studied in the laboratory to understand thermal etching and to limit its effect when this material is used as a catalyst. Yet, in many industrial applications the surface of rolled silver sheets is used without particular surface preparation. Here, it is shown by combining FIB-tomography, FIB-SIMS and analytical SEM that the kinetics of thermal etch pitting are significantly faster on rolled Ag surfaces than on polished surfaces. This occurs due to range of interacting phenomena including ( $i$ ) the reaction of subsurface carbon-contamination with dissolved oxygen to form pores that grow to intersect the surface, (ii) surface reconstruction around corrosion pits and surface scratches, and (iii) sublimation at low pressure and high temperature. A method to identify subsurface pores is developed to show that the pores have $\{111\}$ and $\{100\}$ internal facets and may be filled with a gas coming from the chemical reaction of oxygen and carbon contamination.
\end{abstract}

Keywords: Silver; Subsurface; Thermal Etching; Pore ; Slice \& View; SIMS.

\section{Introduction}

Silver is used as a catalyst in numerous chemical reactions including $\mathrm{NH}_{3}$ decomposition, $\mathrm{CO}$ disproportionation, $\mathrm{H}_{2}$ oxidation, partial oxidation of methanol to formaldehyde and oxidation of ethylene to ethylene epoxide and is therefore an important metal for the chemical industry $[1,2,3,4]$. When silver is heated at high temperature (e.g. $T>873 \mathrm{~K}$ ) its surface undergoes pronounced morphological changes, called "thermal etching" which includes: grain boundary grooving, etch pitting and the formation of striations $[5,6]$. These morphology changes can be considered from a thermodynamic point of view, as the system being driven by the minimisation of the total Gibbs energy. However surface changes occur at lower temperature than bulk changes, as these transformations require mass transfer which is more easily achieved by diffusion at the gas/solid interface. Additionally it has been shown that the surface changes can be modified by a reacting atmosphere surrounding the surface. The reaction-induced changes, sometimes called catalytic etching, often occur at lower temperature than thermal etching and are mainly driven by kinetic considerations [7]. In the case of silver surfaces, the presence of $\mathrm{O}_{2}$ will enhance the formation of striations and grain boundary grooving while an inert atmosphere ( $\mathrm{N}_{2}$ or argon) will prevent many of the morphology changes [8]. Note that solid silver can exist in equilibrium with $\mathrm{O}_{2}$ gas (without an oxide layer) between $\approx 463-1234 \mathrm{~K}$ [9].

Observations of morphological changes occurring on silver surfaces exposed to high temperature, and in different atmospheres have been extensively studied during the $20^{\text {th }}$ century $[10,11,12,13]$ and great efforts have been dedicated to

\footnotetext{
* Corresponding author

Email address: o.maelig@imperial.ac.uk (M. Ollivier)
}

the study of the key role of subsurface oxygen in these surface transformations [14, 3, 15, 16]. However, the laboratorypolished surfaces used in these studies are not representative of the silver used in many industrial situations. In a previous work [17], we reported the formation of etch pits and nanometre to micrometre-sized subsurface pores growing with time and temperature in rolled silver sheets heat treated in air. A direct correlation between the rolling process and the formation of such pores was demonstrated. Surface and subsurface carbon-rich impurities forming strips more than $100 \mu \mathrm{m}$ in length along the rolling direction were often observable in 'as-received' silver sheets. Once these sheets are heat treated in air, faceted subsurface pores as well as etch pits develop within the same region as the previous $\mathrm{C}$-rich strips. If the oxygen-rich atmosphere is replaced by an inert gas -e.g. argon-these features do not form and C-rich impurities remain during heating.

That past work [17] indicated that rolled silver surfaces thermally etch differently than laboratory-polished surfaces. Therefore, in this new work, we have performed a systematic study of the influence of a rolled surface on the thermal etching of silver to understand how defects in the rolled surface influence thermal etching. This includes a comparison between rolled and polished silver surfaces in air at atmospheric pressure and in a $1 \mathrm{~Pa}$ vacuum at temperatures ranging from 773-1073 K.

\section{Experimental section}

\subsection{Material \& Preparation Methods}

The experiments were performed with $1 \mathrm{~cm}$-squared coupons of polycrystalline (mean grain size $20 \mu \mathrm{m}$ ) silver sheets of $0.5 \mathrm{~mm}$ thickness and with a purity of $99.99 \%$. The main impurities of the silver batch used are given in Table 1. The impu- 
Table 1 Main chemical impurities (wt ppm) of the silver batch used in this study. The impurity levels have been measured by different techniques as described in the text.

\begin{tabular}{cccccccccccc}
\hline $\mathrm{O}$ & $\mathrm{Pb}$ & $\mathrm{Cu}$ & $\mathrm{Zn}$ & $\mathrm{Ni}$ & $\mathrm{P}$ & $\mathrm{Au}$ & $\mathrm{Sn}$ & $\mathrm{Fe}$ & $\mathrm{Mg}$ & $\mathrm{Cd}$ & $\mathrm{Al}$ \\
\hline $20-25$ & 14 & 13 & 3.8 & $<5$ & $<5$ & $<5$ & $<5$ & $<5$ & $<5$ & $<5$ & $<5$ \\
\hline
\end{tabular}

rity levels have been measured with Inert Gas Fusion (IGF) for oxygen, Inductively Coupled Plasma-Atomic Emission Spectroscopy (ICP-AES) for $\mathrm{Pb}, \mathrm{Zn}$ and $\mathrm{Cu}$ and Inductively Coupled Plasma-Optical Emission Spectroscopy (ICP-OES) for the remaining metallic atoms. The silver sheets were processed with the following procedure that is representative of industrial rolling: after a first rolling step decreasing the thickness from $15 \mathrm{~mm}$ to $2 \mathrm{~mm}$, the silver sheet was annealed in a reducing atmosphere for $45 \mathrm{~min}$ at $923 \mathrm{~K}$ then straightened and brushed. A second rolling step was carried out crosswise to decrease the thickness down to $0.7 \mathrm{~mm}$ followed by another annealing in a reducing atmosphere for $45 \mathrm{~min}$ at $923 \mathrm{~K}$. Finally the silver sheet was rolled down to $0.5 \mathrm{~mm}$ then annealed in an inert atmosphere $\left(\mathrm{N}_{2}\right)$ at $623 \mathrm{~K}$ for 4 hours.

As part of this study, the silver coupons were subjected to two surface preparations: (i) cleaned or (ii) polished \& cleaned.

(i) 'As-received' silver sheets were contaminated with organic pollutants (grease, fingerprints), particles coming from manufacturing tools and corrosion products such as $\mathrm{Ag}_{2} \mathrm{~S}$. The cleaning process has been described elsewhere [17] and is made of two steps:

- Silver coupons were put in contact with an aluminium foil in a potassium hydroxide solution $\mathrm{KOH}: \mathrm{H}_{2} \mathrm{O}\left(0.6 \mathrm{~mol} . \mathrm{L}^{-1}\right)$ and heated at $353 \mathrm{~K}$ for $2 \mathrm{~min}$ in order to decompose silver sulphide. Samples were then rinsed with deionised water and dried.

- Organic pollutants and dust were removed using three sonications of $10 \mathrm{~min}$ using acetone $\left(\mathrm{CH}_{3} \mathrm{COCH}_{3}\right)$, methanol $\left(\mathrm{CH}_{3} \mathrm{OH}\right)$ and isopropanol $\left(\mathrm{CH}_{3} \mathrm{CH}(\mathrm{OH})-\mathrm{CH}_{3}\right)$. Samples were then rinsed with isopropanol and directly inserted into the furnace.

(ii) In order to remove surface and subsurface defects induced by the rolling process, some silver coupons were prepared with a three-step process:

- Silver coupons were mounted in a cold mounting resin (VersoCit, from Struers ${ }^{\circledR}$ ), then ground with $\mathrm{SiC}$ papers down to "2000 grit" size.

- Silver samples were polished using diamond suspensions of $6 \mu \mathrm{m}, 3 \mu \mathrm{m}, 1 \mu \mathrm{m}$ and finally $0.25 \mu \mathrm{m}$.

- Samples were then removed from resin and cleaned using three sonications of $10 \mathrm{~min}$ using acetone $\left(\mathrm{CH}_{3} \mathrm{COCH}_{3}\right)$, methanol $\left(\mathrm{CH}_{3} \mathrm{OH}\right)$ and isopropanol $\left(\mathrm{CH}_{3} \mathrm{CH}(\mathrm{OH})-\mathrm{CH}_{3}\right)$. Finally samples were rinsed with isopropanol and directly inserted into the furnace.

\subsection{Heat treatment experiments}

Silver coupons were given heat treatments in different atmospheres (in air at atmospheric pressure, in an inert argon atmosphere at atmospheric pressure or under vacuum), at different temperatures (from 673 to $1073 \mathrm{~K}$ ) and for different dwell times (from 1 to 60 hours). An horizontal furnace made of an alumina tube connected upstream to a gas panel and downstream to a pumping system was used for the heat treatments:

(i) For experiments performed in air at atmospheric pressure, the tube was simply open at both ends.

(ii) For experiments performed in an inert atmosphere at atmospheric pressure the furnace was twice flushed with argon $(99.998 \%)$ before reaching atmospheric pressure. A flow of 20 standard centimetres cubed per minute $(\mathrm{sccm})$ of argon was fixed during the heat treatments.

(iii) For experiments performed under vacuum, the furnace was twice flushed with argon $(99.998 \%$ ) then evacuated to the working pressure of $1 \mathrm{~Pa}$.

\subsection{Characterization techniques}

The surface of the heat treated silver was characterized by Scanning Electron Microscopy (FEG-SEM, Zeiss Auriga) and Electron Back-Scattered Diffraction (EBSD, Quantax Bruker). The subsurface was also investigated by dual column focussed ion beam/SEM microscopy (FIB-SEM, FEI Helios NanoLab 600 ) and focussed ion beam - secondary ion mass spectrometry (FIB-SIMS, FEI FIB200-SIMS) equipped with two electric quadrupole-based, charged particle filters that can be polarised to select and analyse either positive or negative secondary ions on a mass-to-charge ratio basis.

\section{Results \& Discussion}

\subsection{Initial surfaces}

Figure 1 shows typical regions of the silver surfaces before heat treatments in the 'as-rolled' condition and the polished condition. Figures $1 \mathrm{a}$ and $\mathrm{c}$ are FIB secondary electron images of the surfaces where the microstructure is revealed by channelling contrast. Figures $1 \mathrm{~b}$ and $\mathrm{d}$ are SE-SEM images of cross-sections through the surface obtained after trenches were made using the FIB column. In the 'as-rolled and annealed' condition, two populations of grains can be seen at the surface (Figure 1a): larger grains containing twins and bands of much smaller sub-micrometre grains. Note that the bands of smaller grains are parallel to the rolling direction. The FIB cross-sections in Figure $1 \mathrm{~b}$ show that these sub-micrometre 

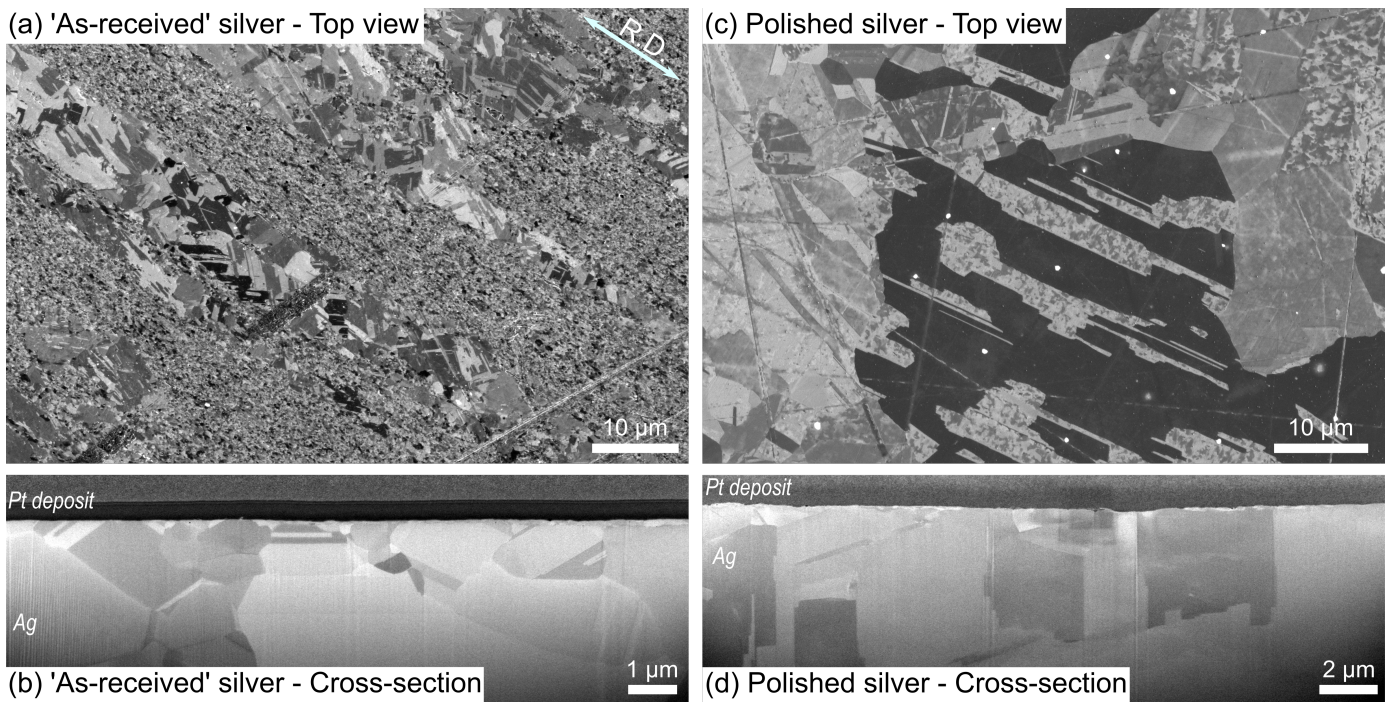

(b) 'As-received' silver - Cross-section

Figure 1 Initial surfaces. (a) FIB secondary electron image of an 'as-received' silver sample. (b) Cross-section SEM image of the subsurface region of an 'as-received' silver sample. (c) FIB secondary electron image of a polished silver sample. (d) Cross-section SEM image of the subsurface region of a polished silver sample.

grains exist only near the surface (within the top $0.5 \mu \mathrm{m}$ from the surface) and coarser grains exist below. It can also be seen that many of the grains contain annealing and recrystallization twins. After polishing, most of the smaller grains were removed (Figures 1c and d) and some polishing damage can be seen in the near-subsurface.

\subsection{The thermal etching of polished silver}

For silver samples polished and then heat treated in air at atmospheric pressure, the characteristic features described in the literature were observed as overviewed in Figure 2. Figure 2 a shows typical examples of grain faceting. Silver surfaces of different grains orientations have developed into multiple low-index planes in order to reduce the total surface energy. This phenomenon can also be described from a kinetic point of view via the surface diffusion of silver atoms in a chemical gradient between non-equilibrium surfaces toward equilibrium ones. It is also accompanied by the increase of the total surface area $[18,19,7]$. Figure $2 b$ shows that grain-boundaries are also impacted by the thermal etching, and grooves develop. This grooving is generally explained by the combination of $(i)$ the equilibrium between the grain boundary tension and the two surface tensions, leading to the surface diffusion of atoms and (ii) the sublimation of atoms in the vicinity of the grainboundary [20, 21, 22, 23, 24]. Additionally, at localised places, faceted etch pits can be observed (Figure 2c). The growth of etch pits is a complex subject, mostly because etch pitting is generally described from a phenomenological point of view and more than one phenomenon are gathered under this term. In the literature, the etch pitting of silver surfaces during thermal etching is often described in terms of dislocation revelation $[25,26,27,28]$.

In contrast, when the heat treatment of polished silver surfaces is carried out under vacuum, the impact of oxygen is limited and the surface remains smooth except at high tempera- ture. In those cases where sublimation with weight loss has been recorded surface roughening (see Figure 3 ) is observed.

\subsection{The thermal etching of rolled silver}

The morphology changes of a silver surface occurring during a thermal treatment were found to be significantly different when the rolled surface was tested. The manufacturing process and defects induced by rolling as well as corrosion pits and scratches modified the effect of thermal etching: each of these will be considered in turn.

\subsubsection{Subsurface pore growth}

As can be seen on the Figures $4 \mathrm{a}-\mathrm{c}$ when an 'as-rolled' and cleaned silver sample is heat treated in air at $1073 \mathrm{~K}$ for $60 \mathrm{~min}$, it is thermally etched: its surface develops into multiple facets, grain-boundaries groove, and etch pitting occurs as on a polished surface. However, it is noteworthy that the etch pits are in this case aligned along the rolling direction (unlike on polished surfaces where etch pits are found on local places). When FIB sputter etching is carried out across a line of surface etch pits, faceted subsurface pores are also revealed (see Figure 4b).

A systematic FIB-SEM characterization via Slice \& View (S\& V) of the subsurface pores has been performed in order to analyse the growth of such pores during heat treatments in air, for five temperatures (673-773-873-973-1073 K) and three different dwell times (60-360-720 min). The result of this study is presented in Figure $4 \mathrm{~d}$. The pores are approximated as spheres, and the size of each pore is plotted using the volume of the largest pore found in each $\mathrm{S} \& \mathrm{~V}$ experiment. It is clear that the size of subsurface pores is growing with time and temperature, however the correlation between growth parameters and the size of the pores cannot be determined accurately due to the relatively low number of pores milled via FIB-SEM. The volume probed by $\mathrm{S} \& \mathrm{~V}$ for each sample is about $9000 \mu \mathrm{m}^{3}$ 


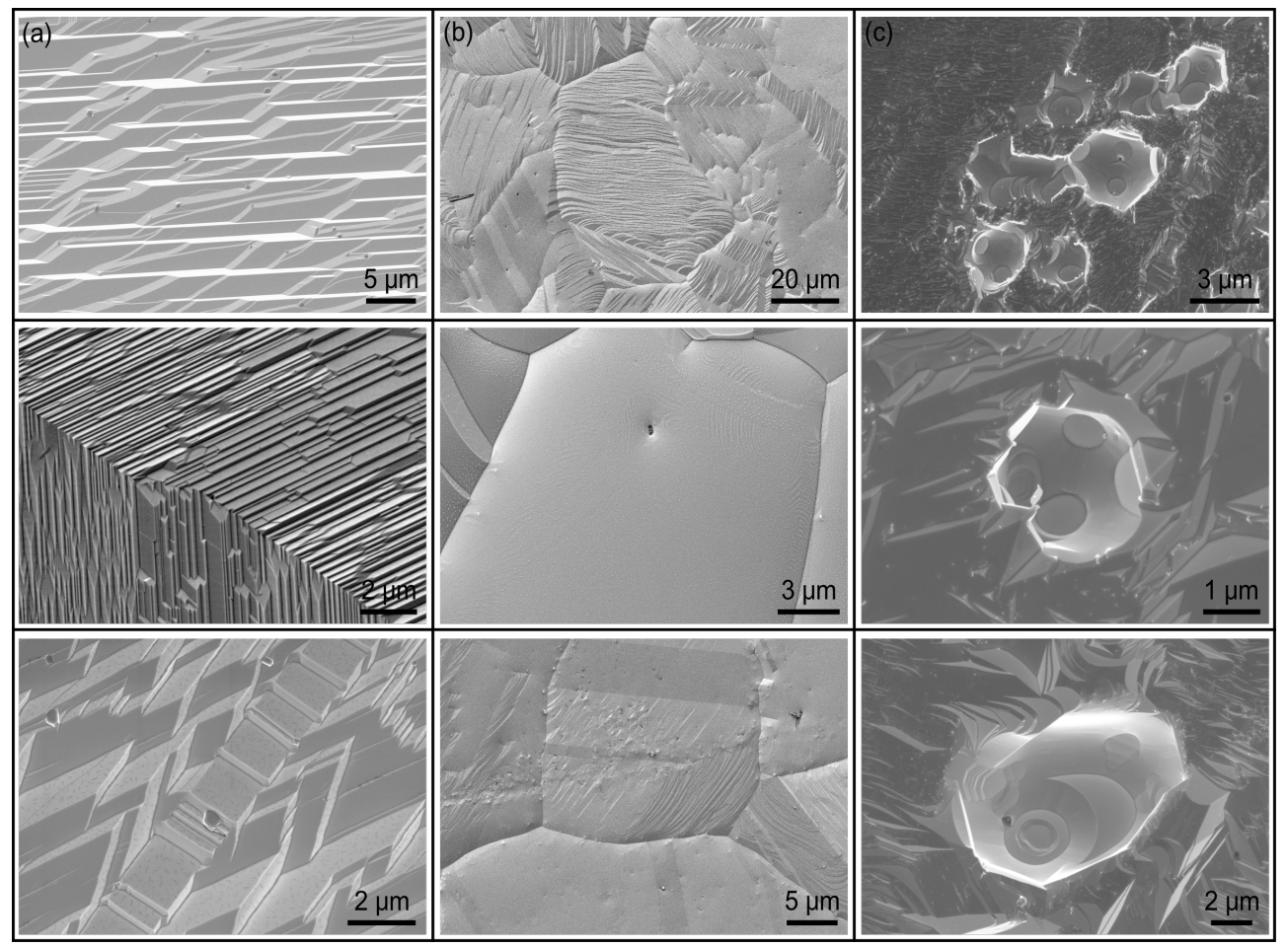

Figure 2 SEM images of the main features found on a silver surface heat treated in air. (a) Grain faceting. (b) Grain boundary grooving. (c) Etch pitting.

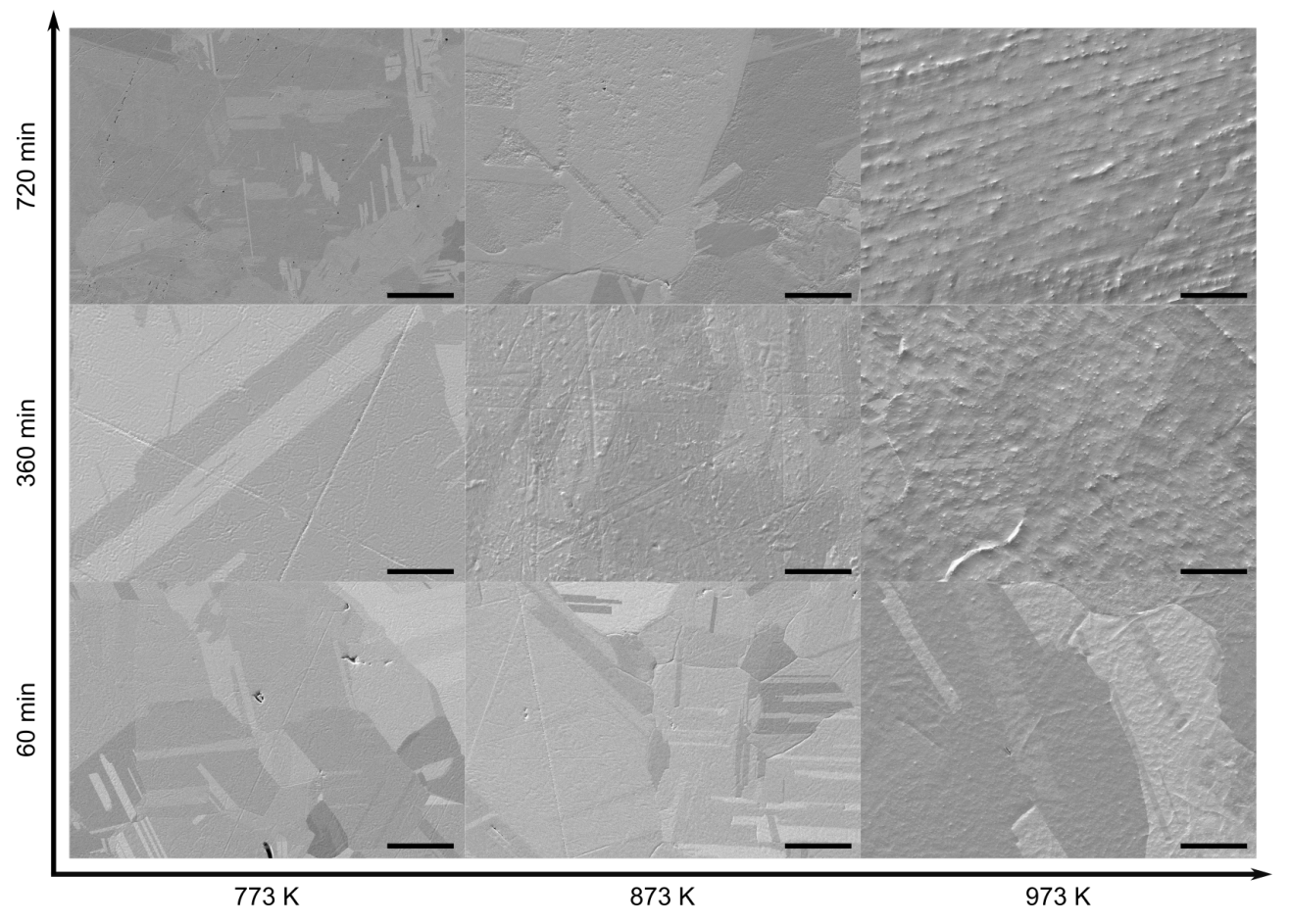

Figure 3 SEM images after heat treatments under vacuum (1 Pa) of polished silver surfaces. Temperature range 773 to $973 \mathrm{~K}$; dwell time from $60 \mathrm{~min}$ to $720 \mathrm{~min}$. Scale bars $=20 \mu \mathrm{m}$.

and no complete statistics could be obtained from such a small statistical sample. Note that subsurface pores did not grow in samples that had been polished.

\subsubsection{FIB tomography of a subsurface pore}

One can deduce from the previous paragraph and from Figure 4 that the main challenge of subsurface pore characterization is to locate the pores. Thanks to the presence of aligned 


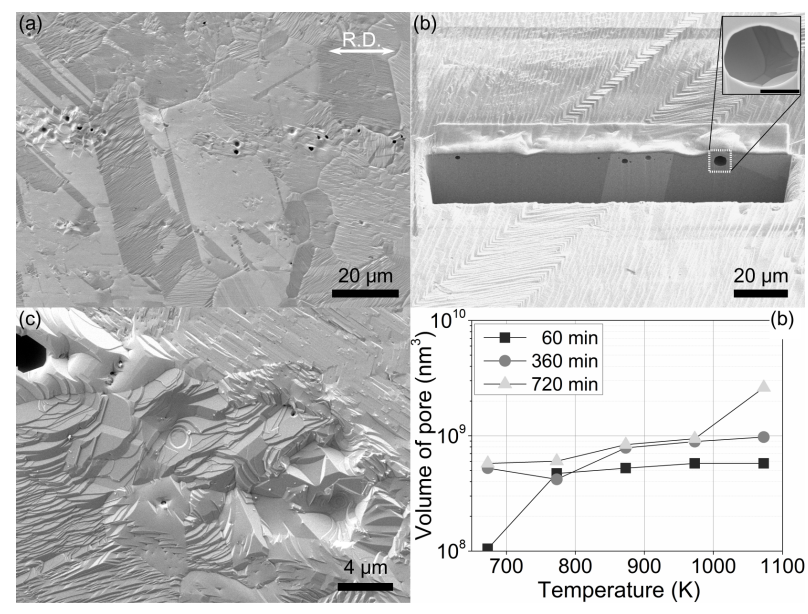

Figure 4 (a) SEM image of the surface of a silver sample heat treated in air for $60 \mathrm{~min}$ at $1073 \mathrm{~K}$. A line of etch pits -parallel to the rolling direction (RD)- is highlighted. (b) FIB cross-sectioned SEM image of the same silver sample where subsurface faceted pores are observable. Inset, a higher magnification image of a pore, scale bar $=1 \mu \mathrm{m}$. (c) High magnification SEM image of a zone with etch pits. (d) Graph showing the evolution of the size of the largest subsurface pores as a function of time and temperature (y-axis in log scale).

etch pits, which are linked to the subsurface pores as has been shown elsewhere [17] it is possible to find with a high probability the pores aligned with the etch pitting. However, there is another way to locate subsurface pores as long as these latter are close to the surface. By increasing the accelerating voltage of electrons in the SEM column, switching from $5 \mathrm{keV}$ to $30 \mathrm{keV}$ for example, electrons will pass through the summit of subsurface pores and no signal will be detected coming from this region, leading to a darker zone on the SEM image. This phenomenon is illustrated with the two SEM images presented on the Figures $5 \mathrm{a}$ and $5 \mathrm{~b}$. These SEM images have been taken on the same silver sample heat treated in air for $3600 \mathrm{~min}$ at $1073 \mathrm{~K}$. An accelerating voltage of $5 \mathrm{keV}$ has been used for Figure 5a, and $30 \mathrm{keV}$ has been used for Figure 5b, where the presence of a pore is revealed by a darker region at higher accelerating voltage (in the region highlighted by a dashed box).

Thanks to the phenomenon described above, it has been possible to make a detailed characterization of this particular pore. First, the crystal orientation of the Ag surrounding the pore has been determined by EBSD (see Figures $5 c$ and $f$ ). Then a detailed $\mathrm{S} \& \mathrm{~V}$ of the pore has been recorded. This $\mathrm{S} \& \mathrm{~V}$ is made of 380 slices with a step of $\approx 13 \mathrm{~nm}$.

Two individual slices of the $S \& V$ are presented in Figures $5 d$ and $5 \mathrm{e}$, corresponding to the steps \#100 and \#210, respectively. It is interesting to note the straight segments of the cross-section, corresponding to the facets of the pore. Also, it is noteworthy that the facets are circular and slightly concave. Between these facets complex crystalline planes can be seen. The pore has also been reconstructed in 3 dimensions with the "FIB Stack Wizard" of Avizo ${ }^{\odot}$ software (FEI). This $3 \mathrm{D}$ view is presented on the Figure $5 \mathrm{~g}$, where the 3 axes $\vec{a}$, $\vec{b}$ and $\vec{c}$ correspond to the FCC crystallographic orientation of silver, based on EBSD acquisition. A movie of the 3D pore reconstruction rotating around the $\vec{c}$ axis is available as a Supplementary Material. The pore had a diameter of about $4.8 \mu \mathrm{m}$, and 14 circular facets. It can be seen from the 4 different views displayed that the facets are preferentially parallel to the $\{111\}$ and $\{100\}$ planes. In 1965, Nelson et al. [29] discussed the equilibrium shapes of holes in solids. According to their work, when $\{111\}$ and $\{100\}$ planes develop in a FCC crystal, a truncated octahedron with 14 facets is obtained, which corresponds to the number of facets of the pore in Figure 5, as well as the facet orientations observed. However, the equilibrium shape is not fully reached since the 14 facets are not touching each other in Figure 5g. Also, since silver can be subject to thermal etching, the atmosphere -or the absence of atmosphere- may have a key role in the surface morphology of the inside surface of the pore. For this reason an effort was dedicated to answer the question: What is inside the subsurface pores?

\subsubsection{Determination of gas trapped in pores}

In order to answer this question, FIB-SIMS characterization was conducted on the 'as-received' silver sample heat treated in atmospheric air for $3600 \mathrm{~min}$ at $1073 \mathrm{~K}$. Thanks to the localisation of subsurface pores via the tuning of electron acceleration in the SEM column, selective SIMS measurements have been conducted on 6 pores. Typically, a $5 \times 5 \times 5 \mu \mathrm{m}$ box containing a pore was milled with the ion beam (FIB voltage $30 \mathrm{keV}$, current $1000 \mathrm{pA}$ ), while the chosen atomic masses were monitored. The choice of the atomic masses to monitor is crucial. The observation of pores in the subsurface region occurring during thermal treatments of silver has been briefly described in a few studies from Klueh \& Mullins [30, 31] and from Bao et al. [6]. Their hypothesis was based on the dissolution of $\mathrm{H}$ and $\mathrm{O}$ in the silver, followed by the formation of $\mathrm{H}_{2} \mathrm{O}$ vapour in the subsurface termed the Liesgang phenomenon [32]. Moreover, since carbon species have been detected within the subsurface region of the 'as-received' silver samples used here, and since the presence of oxygen is necessary to observe faceted pores, it was chosen to monitor the $\mathrm{CO}^{+}$atomic mass, as well as $\mathrm{H}_{2} \mathrm{O}^{+}$.

The result of one FIB-SIMS characterization is presented on the Figure 6. The SEM images of Figure $6 \mathrm{a}$ and $6 \mathrm{~b}$ have been taken respectively before and after the FIB sputter etching of a $5 \times 5 \times 5 \mu \mathrm{m}$ box containing the pore. The graph presented in Figure $6 \mathrm{c}$ corresponds to the monitoring of the 2 atomic masses 18 and 28, before, during and after FIB milling. The milling start is indicated with an arrow and the milling time was $60 \mathrm{~s}$. A peak is detected for the 28 atomic mass after the start of milling, which strongly suggests the presence of the $\mathrm{CO}_{2}$ and/or $\mathrm{CO}$ molecules within the pore. However, in the five remaining pores studied by FIB-SIMS, we were unable to detect these species either due to their absence or sensitivity in the experiment.

This result in Figure 6 seems to validate the hypothesis of the reaction of carbon species in the subsurface region with oxygen dissolved in silver. However, it is difficult to conclude because of the small number of pores probed (6), and the even smaller number of positive results obtained (1). Many parameters can explain the non-reproducibility of the measurement. From a scientific point of view, it can be supposed that all the pores do 

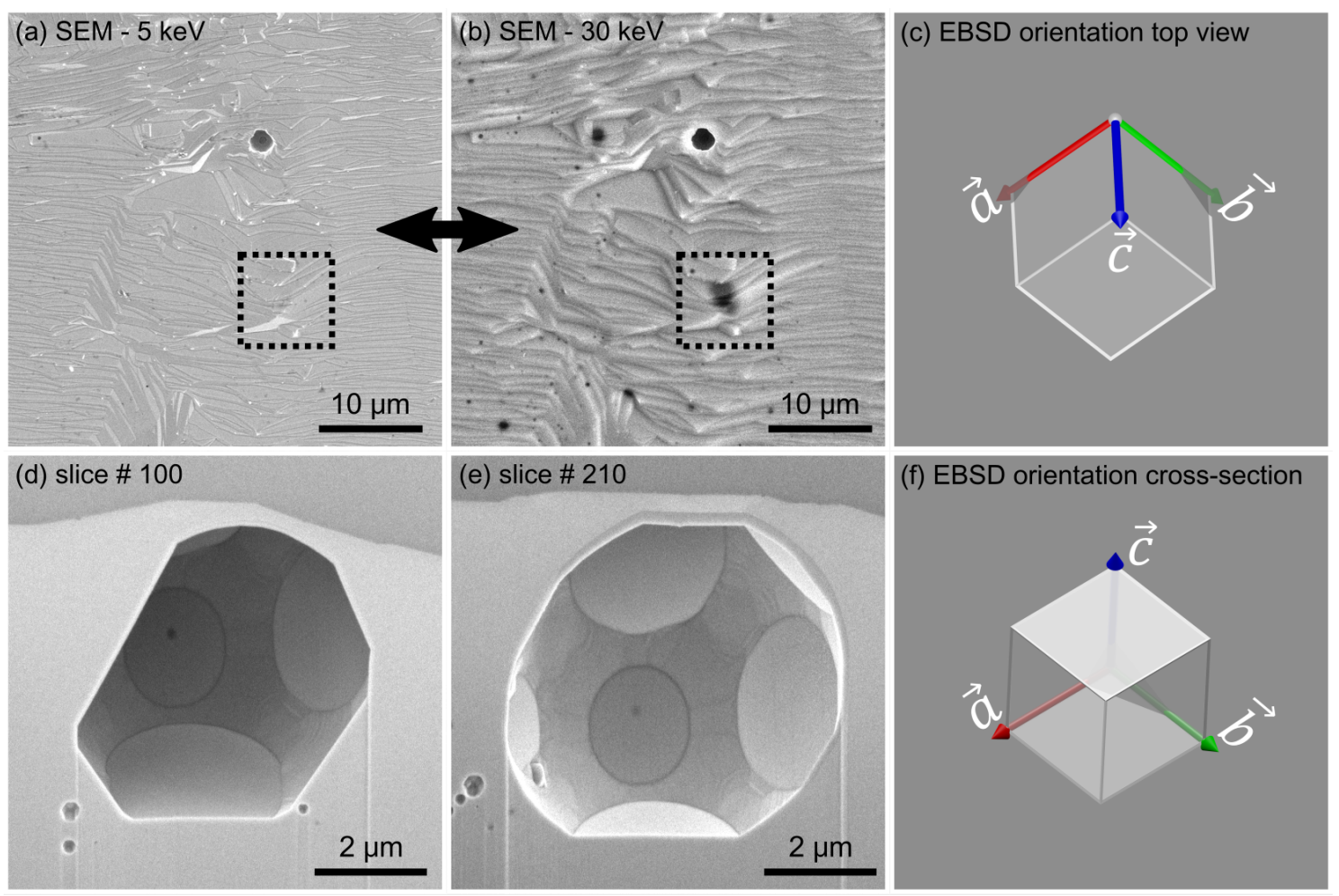

(g) 3D reconstruction
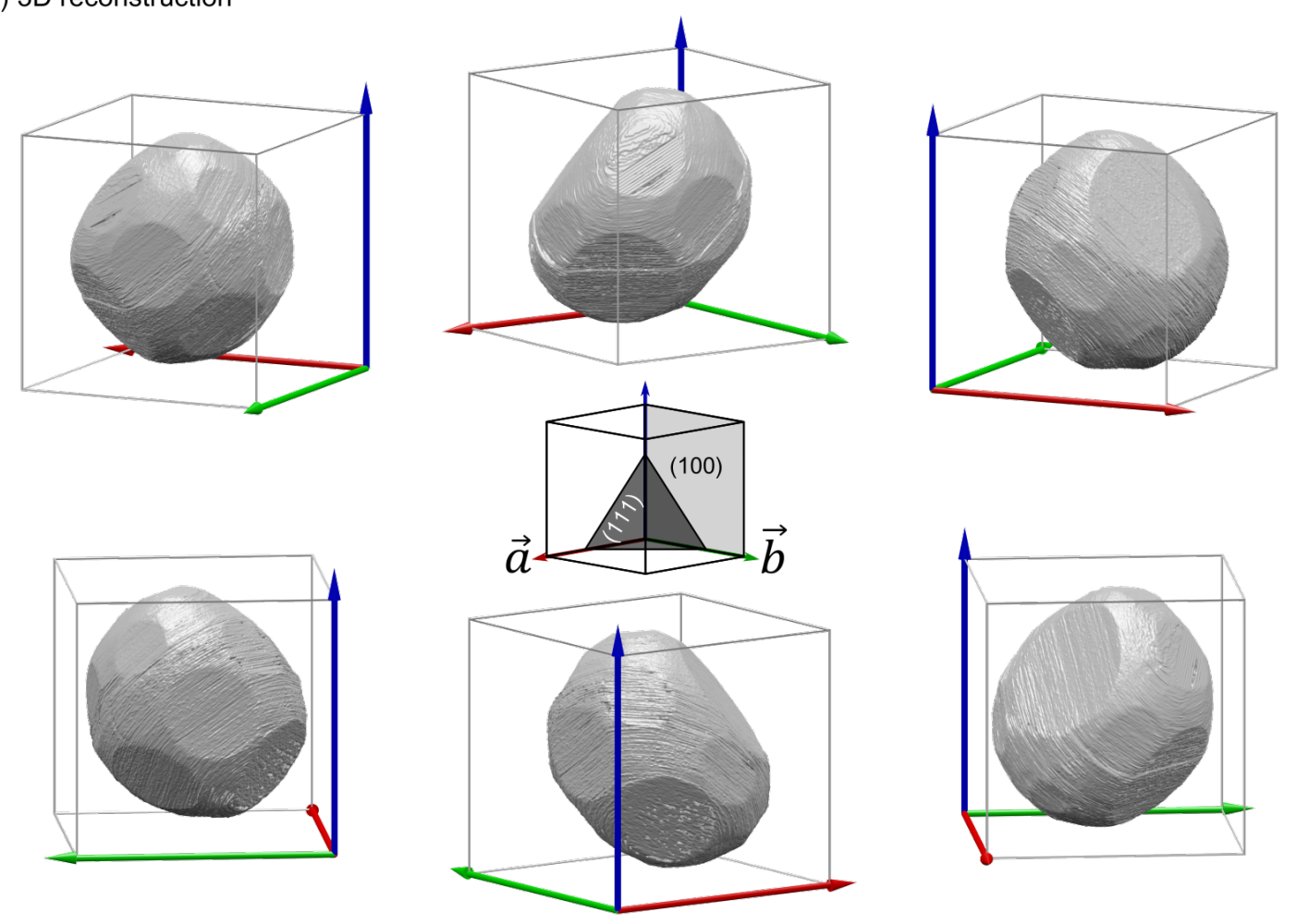

Figure 5 (a) SEM image of silver surface taken with an accelerating voltage of $5 \mathrm{keV}$. (b) Same silver region with an accelerating voltage of $30 \mathrm{keV}$, a subsurface pore is localised. The zone probed with FIB-SEM S\&V is framed. (c) Crystallographic orientation of the silver grain obtained by EBSD and corresponding to SEM images (a) and (b). (d-e) SEM images taken during the S\&V of the subsurface pore, Slice \#100 and \#210. The images have been stretched to correct the tilt angle $\left(52^{\circ}\right)$. (f) Crystallographic orientation of the silver grain obtained by EBSD oriented to correspond to the orientation of the SEM images (d) and (e). (g) 3-dimensional reconstruction of the pore where circular facets are visible. The $\vec{a}, \vec{b}$ and $\vec{c}$ axis correspond to the FCC crystallographic axes of silver. 


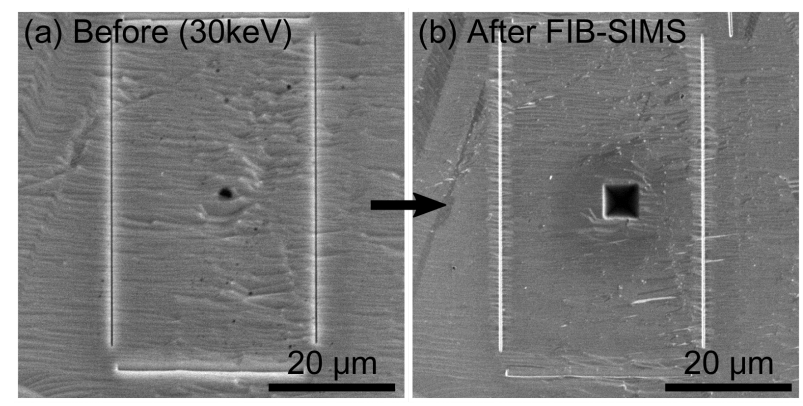

(c) SIMS measurement

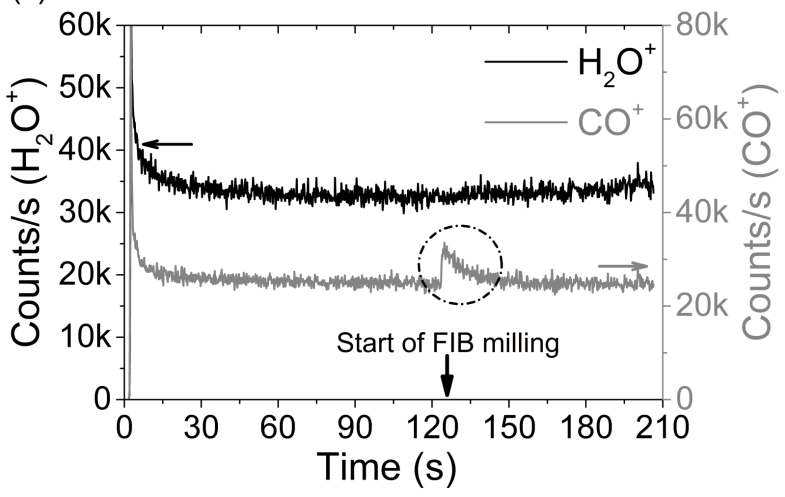

Figure 6 Rolled silver sample heat treated in atmospheric air for $3600 \mathrm{~min}$ at $1073 \mathrm{~K}$. (a) SEM image of a subsurface pore localised by increasing the accelerating voltage (30 keV). (b) SE image of the same zone after a $5 \times 5 \mu \mathrm{m}$ box has been etched by FIB sputter. (c) Graph presenting the monitoring of the atomic masses 18 and 28 , respectively for $\mathrm{H}_{2} \mathrm{O}^{+}$and $\mathrm{CO}^{+}$during FIB sputter etching of the subsurface pore. $\mathrm{A} \mathrm{CO}^{+}$peak is visible when the pore is opened. FIB voltage $30 \mathrm{keV}$, current $1000 \mathrm{pA}$.

not contain $\mathrm{CO}_{2} / \mathrm{CO}$ molecules; however, two different mechanisms in the same experimental conditions leading to the same formation of pores seem to be unlikely. On the other hand, this is a difficult measurement to carry out and a number of factors would need to be in place to enable pore gas detection: the pore would need to contain a sufficient quantity of gas (i.e. be of a sufficient volume and pressure) and released in a burst as short as possible to enable detection. For example, if the milling of the pore is performed in such way that a small hole is firstly made leading to a small leak, the detection limit may not be reached. Thus, our results are consistent with $\mathrm{C}$-impurities reacting with dissolved oxygen, producing $\mathrm{CO}$ or $\mathrm{CO}_{2}$ gas in a subsurface pore but this is difficult to prove conclusively.

This mechanism is further validated by the study of large blisters aligned with etch pits on as-rolled silver samples annealed under vacuum. These blisters may be due to larger Ccontamination in the subsurface region. One can see for example in Figure 7a a blister on a non-polished silver sample annealed under vacuum at $873 \mathrm{~K}$ for $60 \mathrm{~min}$. Once FIB milling is carried out on that larger blister (see Figure $7 \mathrm{~b}$ ), a pore is observable, which still contains some C-contamination. It can be inferred that the blister is due to some gas trapped inside the pore applying a pressure on the surface at elevated temperature. If this surface is broken, for example where there are smaller grains (see Figure 1), an etch pit will be formed. On the contrary, when the heat treatments are performed in an inert atmosphere (argon flow $20 \mathrm{sccm}$ at atmospheric pressure) the $\mathrm{C}$-contamination remains on and under the surface even at high temperature $(>1073 \mathrm{~K})$, as it can be seen on the Figures $7 \mathrm{c}$ and $\mathrm{d}$. Presumably the low partial pressure of oxygen in this case results in a reduced flow of oxygen into the sample, and this in turn results in a negligible reaction between $\mathrm{C}$ contamination and oxygen. These results confirm the key role of $\mathrm{O}_{2}$ and $\mathrm{C}$-contamination in the growth mechanism of subsurface pores, and support the FIB-SIMS characterisations. Thus, we attribute the formation and growth of subsurface pores to a reaction of subsurface $\mathrm{C}$-contamination and oxygen introduced into the metal at high temperatures.

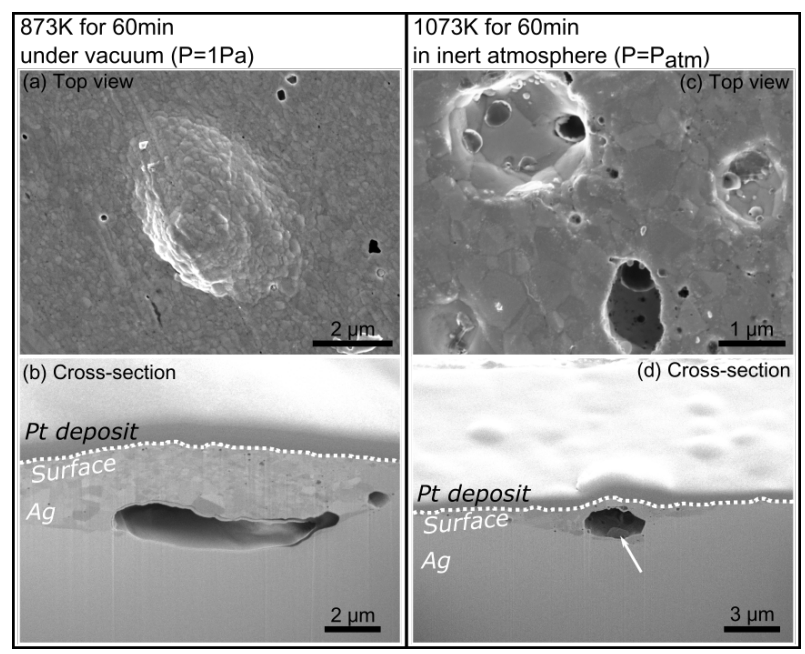

Figure 7 (a)-(b) SEM images of a blister found on the surface of a silver sample heat treated under vacuum $60 \mathrm{~min}$ at $873 \mathrm{~K}$; the cross-section after FIB milling shows that the blister is due to a pore growing in the subsurface region. (c)-(d) SEM images of C-contamination on the surface of a silver sample heat treated at atmospheric pressure under argon $60 \mathrm{~min}$ at $1073 \mathrm{~K}$; the cross-section after FIB milling shows that $\mathrm{C}$-contamination is still present after annealing in an inert atmosphere (arrow).

\subsubsection{Effect of surface defects on etch pitting}

When 'as-rolled' silver surfaces are heat treated under vacuum, the morphology changes enhanced by oxygen are reduced, and the impact of surface defects such as scratches and corrosion pits is easier to characterize. Thus, a set of experiments has been conducted under vacuum $(\mathrm{P}=1 \mathrm{~Pa})$ on nonpolished silver samples.

The results of these experiments are presented in Figures 8a and b. As can be directly seen in the SEM images of Figure 8 no facets/striations or grain-boundary grooves developed on the silver surface when the heat treatment is carried out under vacuum (similar to polished surfaces, cf. Figure 3 ). In Figure 8 it is possible to see the behaviour of defects found on 'as-rolled' surfaces as a function of time and temperature. Firstly, the carbon contamination strips are at the origin of aligned faceted etch pits at higher temperature/time. However, surface reconstruction around defects such as scratches and corrosion pits can also lead to etch pitting. 

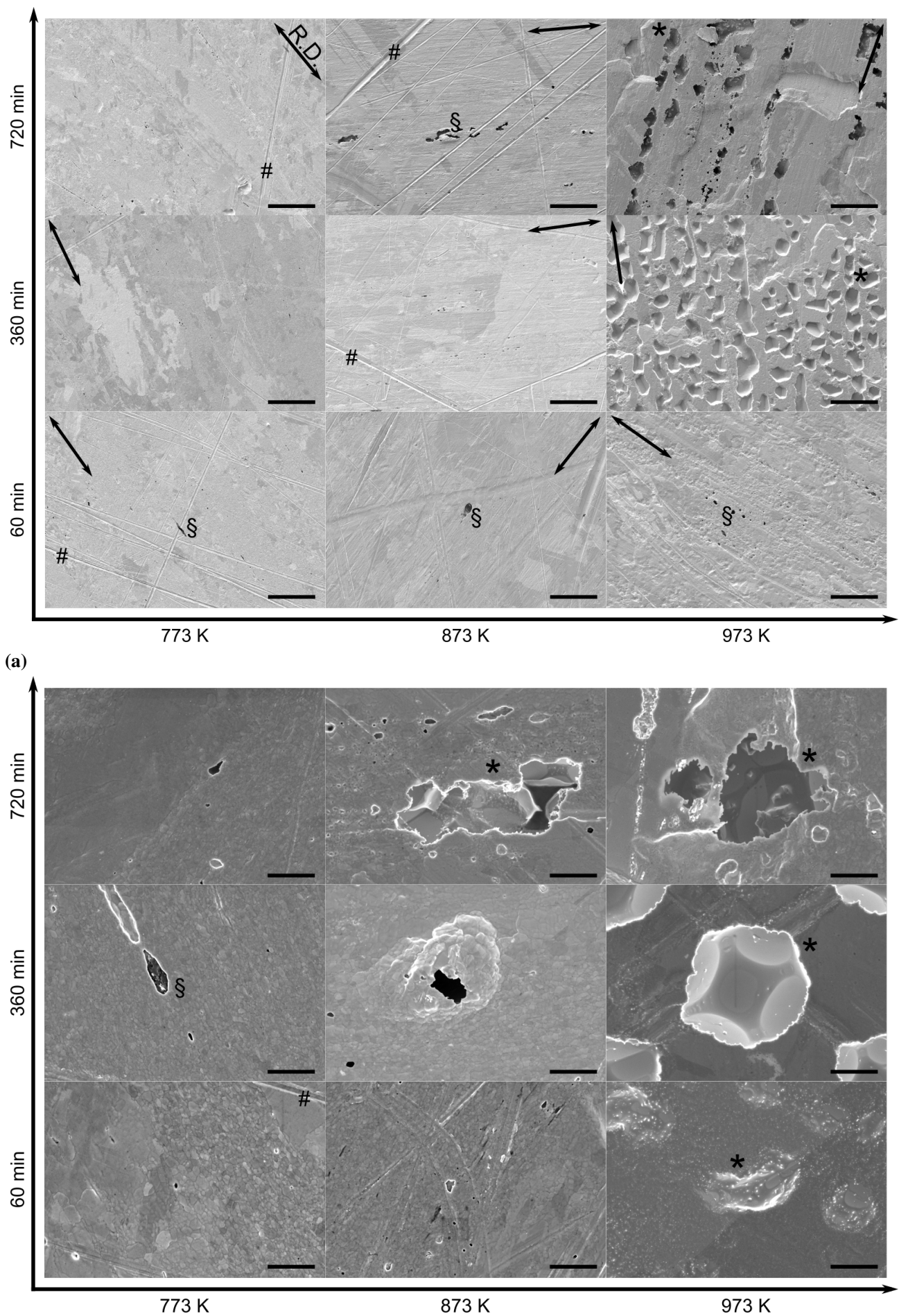

(b)

Figure 8 SEM images after heat treatments under vacuum (1 Pa) of silver surfaces not polished but cleaned. (a) Low magnification, scale bars $=20 \mu \mathrm{m}$. (b) High magnification, scale bars $=1 \mu \mathrm{m}$. Temperature range 773 to $973 \mathrm{~K}$; dwell time from $60 \mathrm{~min}$ to $720 \mathrm{~min}$. Label \# corresponds to scratches, label $*$ corresponds to etch pits and label $\S$ corresponds to C contamination. The rolling direction is indicated with an arrow.

For example, it is possible to compare the surface of an asrolled silver sample before and after heat treatment under vacuum. An SEM image of this sample is presented on Figure 9a, where a cross-mark has been milled with an ion beam. The rolling direction is indicated with an arrow, and scratches are also visible (labelled \#), as well as defects induced by atmo- 


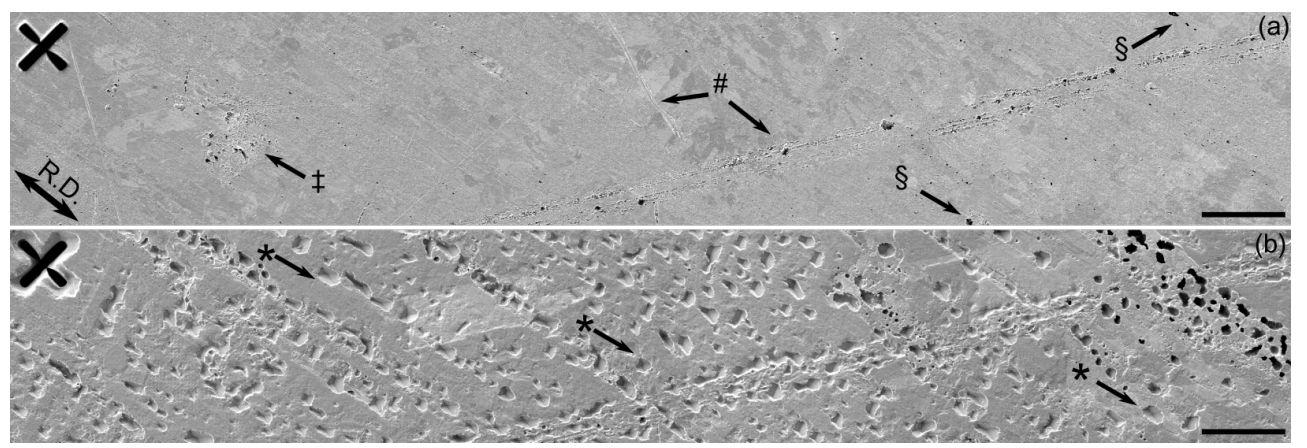

Figure 9 (a) SEM image of a rolled silver sample where a cross-mark has been milled. (b) Same silver sample heat treated for 60 min at $973 \mathrm{~K}$ $(\mathrm{P}=1 \mathrm{~Pa})$. Label $\ddagger$ refers to corrosion defects; label \# refers to scratches; label $*$ refers to etch pits and C-contamination is indicated with label $\S$. Scale bar $=20 \mu \mathrm{m}$.

spheric corrosion (labelled with $\ddagger$ ) and C-contamination (labelled §). The same area after heat treatment is presented on Figure $9 \mathrm{~b}$. It is clearly visible that most faceted etch pits are aligned with the rolling direction however, defects found on the initial surface such as corrosion pits or scratches also appear to be responsible for subsequent etch pits.

In the present case, the aligned etch pits cover the whole $\mathrm{cm}^{2}$ surface and are not dependent on grain orientation (however, individual facets on the etch pits do show a dependency on grain orientation). Thus, the hypothesis of dislocation revelation cannot entirely explain the etch pitting. The hypothesis which can be made is that the etch pits are a combination of subsurface pores that grew to intersect the surface for the aligned etch pits (cf. Figure 4), and surface and near surface reconstruction around defects for the others. Moreover, the etch pitting occurs here under vacuum at high temperature and therefore the sublimation of silver has to be taken into account to in order to explain the growth of etch pits.

In order to prove that under vacuum, the sublimation of silver has an impact on etch pitting a silver sample was covered with an inert $\mathrm{Al}_{2} \mathrm{O}_{3}$ sheet on half of its surface, leaving then one side of the sample free for sublimation, and then held under vacuum at $973 \mathrm{~K}$ for $360 \mathrm{~min}$ (see Figure 10). It can be seen that etch pits develop on both sides of the sample and etch pitting is much more pronounced where sublimation was permitted: in the non-covered zone (Figure 10b) etch pitting almost covers the whole surface while in the zone covered with $\mathrm{Al}_{2} \mathrm{O}_{3}$ (Figure 10c) etch pits are less numerous, but still aligned with the rolling direction.

\subsubsection{Quantification of etch pitting under vacuum}

An attempt to quantify the etch pitting phenomenon observed on rolled silver surfaces heat treated under vacuum has been carried by processing the SEM images with the ImageJ software. Starting with 10 SEM images of different magnification for each experiment, the threshold is tuned in order to select only the apparent projected surface area of each individual etch pit. The SEM image is then transformed into a binary image, and with the particle analysing tool of ImageJ, the etch pits are counted (see Figure 11a).

The first result obtained by this method is the observation of
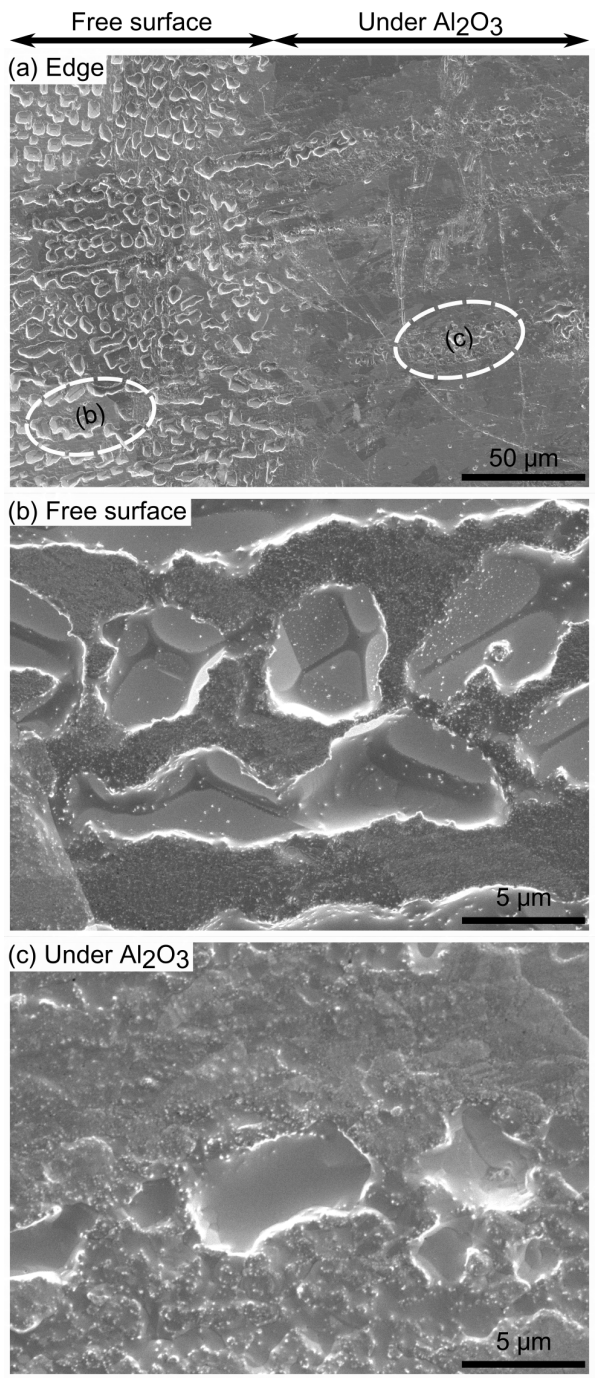

Figure 10 (a) SEM image of a rolled silver sample which has been covered with an $\mathrm{Al}_{2} \mathrm{O}_{3}$ sheet on half of its surface and then heat treated for $360 \mathrm{~min}$ at $973 \mathrm{~K}(\mathrm{P}=1 \mathrm{~Pa})$. (b) Zone not covered where evaporation occurred. (c) Zone covered with $\mathrm{Al}_{2} \mathrm{O}_{3}$ where etch pitting coming from defects induced by rolling are observable. 

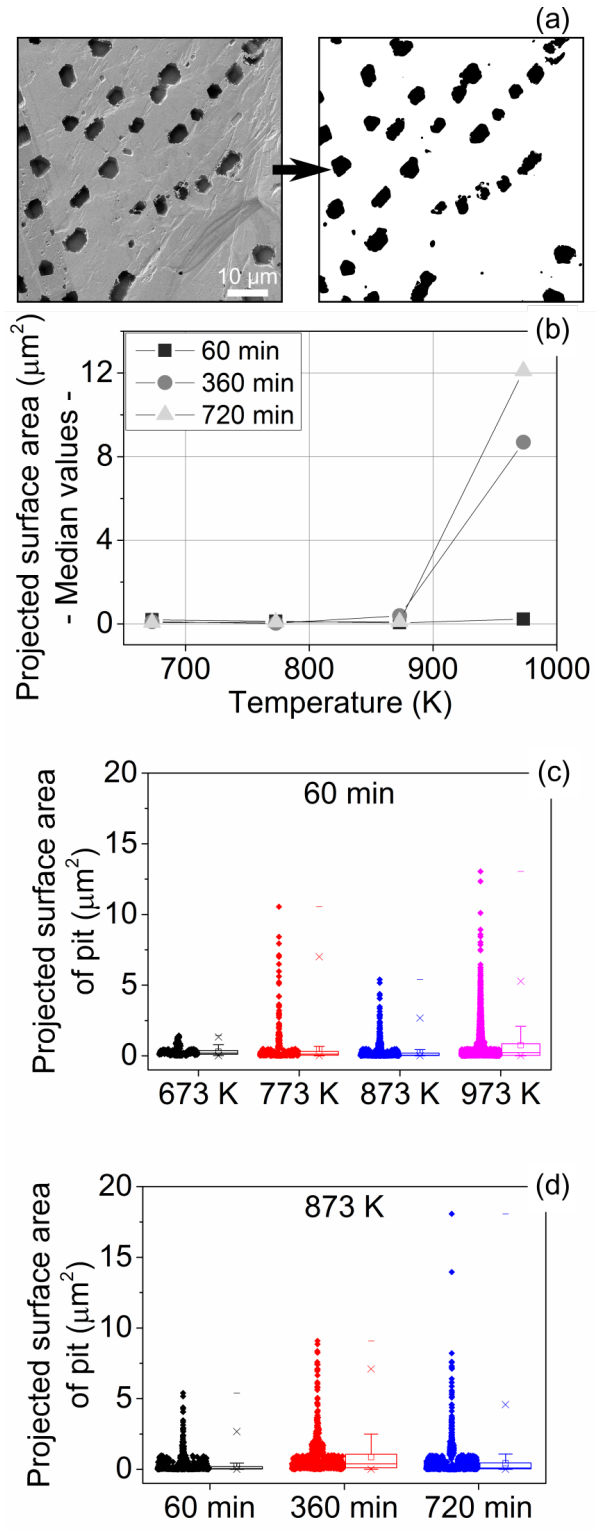

Figure 11 (a) SEM image of silver surface -heat treated under vacuum $720 \mathrm{~min}$ at $973 \mathrm{~K}$ - before (left) and after (right) being processed with ImageJ to quantify the etch pitting. (b) Median projected surface area of etch pits found on silver surface of 'as-received' samples heat treated under vacuum $(\mathrm{P}=1 \mathrm{~Pa})$, as a function of time and temperature. (c) Box chart presenting the distribution size of etch pits as a function of temperature, for $60 \mathrm{~min}$ of heat treatments. (d) Box chart presenting the distribution size of etch pits as a function of time, for different heat treatments performed at $873 \mathrm{~K}$. a large number of sub-micrometre pits, generally not faceted and a smaller number of micrometre-size faceted etch pits. The smaller size category will be made up of a variety of features: corrosion defects and surface damage, as well as nucleation sites for etch pitting. The distribution of the size of pits on any given sample follows a power law with many small pits (Diam. $\varnothing<100 \mathrm{~nm}^{2}$ ) and some $\mu \mathrm{m}$-sized pits. These small pits are difficult to categorize: inside this family of pits, will be counted the pits coming from corrosion or defects found on a non-polished surface, but also the nucleation sites of etch pitting. For this reason we chose to use the median value of the projected surface area of pits to plot the size of pits as a function of the time and temperature of the heat treatments. This graph is presented as Figure 11b. The median size of pits increases with time and temperature, and as it could be deduced by the observation of the SEM images of Figure 8b, the faceted etch pits are mostly observable at $973 \mathrm{~K}$. Another way to process the size of etch pits is to plot box charts in order to visualize and compare the different experiments. When comparing heat treatment experiments performed at 4 different temperatures for $60 \mathrm{~min}$, the power law distribution of etch pits is clearly visible (see Figure 11c). Also, the median size of etch pits for the same time is increasing with temperature. The box charts of the Figure 11d shows the distribution of etch pits for heat treatments done at $973 \mathrm{~K}$ for three different dwell times: 60, 360 and $720 \mathrm{~min}$. The median size of etch pits is increasing with time, and the power law distribution is also visible. Moreover, for long time and higher temperature it is interesting to note that some faceted etch pits have an apparent projected surface area larger than $10 \mu \mathrm{m}^{2}$. These etch pits are in fact the coalescence of two, or more, pits.

\section{Conclusion}

The impact of the surface quality on the thermal etching of silver sheets has been studied through heat treatment experiments conducted in various atmospheres and on polished and 'as-rolled' silver samples. It has been verified that on polished surfaces, the different morphology changes are dependant of the atmosphere surrounding the surface: an oxygen-rich atmosphere will lead to the development of facets on the surface as well as grain-boundary grooving and localised etch pitting, while under vacuum, the surface will mostly be impacted by grain growth and sublimation at high temperature. On the other hand, when 'as-rolled' silver sheets are annealed in air at atmospheric pressure, etch pits aligned with the rolling direction have been identified, and subsurface faceted pores have been found under the surface in the vicinity of the etch pits. The facets of these pores seem to be preferentially aligned with the $\{111\}$ and $\{100\}$ planes and the pores are likely to be filled with a gas coming from the chemical reaction of oxygen and carbon contamination probably embedded in the subsurface region during the rolling process. When the effect of oxygen on silver surfaces is minimized by heat treatments under vacuum, it is possible to study the effect of defects induced by the manufacturing process. Corrosion pits, scratches and other defects found on the initial surface will lead to surface reconstruction coming 
in addition to etch pits formed by subsurface pores reaching the surface. Moreover, the sublimation of silver at high temperature enhances the previously cited phenomena all together leading to the damaging and roughening of the surface. An attempt has been made to quantify the damage of 'as-rolled' silver sheets, via the statistical quantification of etch pitting. The distribution of etch pits follows a power law with many small pits and some micrometre-size pits. Due to the faster etch pitting kinetics, the damage to silver surfaces in an industrial scenario will be faster than expected from past work on laboratory-polished silver.

\section{Acknowledgements}

The authors would like to thank Dr K.M. Kareh from the Department of Earth Science \& Engineering of the Imperial College of London for providing advices on the 3D reconstruction of the subsurface pore. R.M. Harker would like to thank N.E. Seagrave for sponsoring this work.

\section{References}

[1] L. Lefferts, J. van Ommen, J. Ross, The silver-oxygen interaction in relation to oxidative dehydrogenation of methanol, Applied Catalysis 31 (2) (1987) 291-308.

[2] J. Serafin, A. Liu, S. Seyedmonir, Surface science and the silver-catalyzed epoxidation of ethylene: an industrial perspective, Journal of Molecular Catalysis A: Chemical 131 (1-3) (1998) 157-168.

[3] A. Nagy, G. Mestl, R. Schlögl, The role of subsurface oxygen in the silver-catalyzed, oxidative coupling of methane, Journal of Catalysis 188 (1) (1999) 58-68.

[4] L. Hannevold, O. Nilsen, A. Kjekshus, H. Fjellvag, Surface reconstruction on noble-metal catalysts during oxidation of ammonia, Applied Catalysis A: General 284 (1-2) (2005) 185-192.

[5] M. Flytzani-Stephanopoulos, L. Schmidt, Morphology and etching processes on macroscopic metal catalysts, Progress in Surface Science 9 (3) (1979) 83-111.

[6] X. Bao, G. Lehmpfuhl, G. Weinberg, R. Schlogl, G. Ertl, Variation of the morphology of silver surfaces by thermal and catalytic etching, Journal of the Chemical Society-Faraday Transactions 88 (6) (1992) 865-872.

[7] T. Wei, J. Phillips, Thermal and catalytic etching: Mechanisms of metal catalyst reconstruction, Advances in Catalysis 41 (1996) 359-421.

[8] G. Rhead, H. Mykura, Thermal etching of silver in various atmospheres, Acta Metallurgica 10 (9) (1962) 843-856.

[9] G. Waterhouse, G. Bowmaker, J. Metson, The thermal decomposition of silver (I, III) oxide: a combined XRD, FT-IR and Raman spectroscopic study, Physical Chemistry Chemical Physics 3 (17) (2001) 3838-3845.

[10] B. Chalmers, R. King, R. Shuttleworth, The thermal etching of silver, Proceedings of the Royal Society of London. Series A, Mathematical and Physical Sciences 193 (1035) (1948) 465-483.

[11] A. Moore, The influence of surface energy on thermal etching, Acta Metallurgica 6 (4) (1958) 293-304.

[12] E. Hondros, A. Moore, Evaporation and thermal etching, Acta Metallurgica 8 (9) (1960) 647-653.

[13] G. Millar, M. Nelson, P. Uwins, In situ imaging of catalytic etching on silver during methanol oxidation conditions by environmental scanning electron microscopy, Journal of Catalysis 169 (1) (1997) 143-156.

[14] A. Nagy, G. Mestl, D. Herein, G. Weinberg, E. Kitzelmann, R. Schlogl, The correlation of subsurface oxygen diffusion with variations of silver morphology in the silver-oxygen system, Journal of Catalysis 182 (2) (1999) 417-429.

[15] G. Waterhouse, G. Bowmaker, J. Metson, Mechanism and active sites for the partial oxidation of methanol to formaldehyde over an electrolytic silver catalyst, Applied Catalysis A: General 265 (1) (2004) 85-101.
[16] T. Rocha, A. Oestereich, D. Demidov, M. Havecker, S. Zafeiratos, G. Weinberg, V. Bukhtiyarov, A. Knop-Gericke, R. Schlogl, The silveroxygen system in catalysis: new insights by near ambient pressure $\mathrm{X}$ ray photoelectron spectroscopy, Physical Chemistry Chemical Physics 14 (2012) 4554-4564.

[17] M. Ollivier, R. Harker, C. Gourlay, Etch pitting and subsurface pore growth during the thermal etching of silver, Philosophical Magazine Lettersdoi:10.1080/09500839.2015.1121298.

[18] C. Herring, Some theorems on the free energies of crystal surfaces, Physical Review 82 (1951) 87-93.

[19] W. Mullins, Theory of linear facet growth during thermal etching, Philosophical Magazine 6 (71) (1961) 1313-1341.

[20] W. Mullins, Theory of thermal grooving, Journal of Applied Physics 28 (3) (1957) 333-339.

[21] W. Mullins, P. Shewmon, The kinetics of grain boundary grooving in copper, Acta Metallurgica 7 (3) (1959) 163-170.

[22] W. Mullins, Grain boundary grooving by volume diffusion, Transactions of the American Institute of Mining and Metallurgical Engineers 218 (2) (1960) 354-361.

[23] A. Piquet, H. Roux, V. T. Binh, R. Uzan, M. Drechsler, Une determination du coefficient d'auto-diffusion de surface avec des pointes a emission de champ (tungstene), Surface Science 44 (2) (1974) 575-584.

[24] V. T. Binh, R. Uzan, M. Drechsler, Une determination du coefficient d'auto-diffusion de surface du molybdene, Surface Science 57 (1) (1976) $118-124$.

[25] A. Hendrickson, E. Machlin, A thermal etching technique for revealing dislocations in silver, Acta Metallurgica 3 (1) (1955) 64-69.

[26] J. Hirth, L. Vassamillet, Correlation of thermal etch pits with dislocations in silver, Journal of Applied Physics 29 (3) (1958) 595-595.

[27] H. Levinstein, W. Robinson, Etch pits at dislocations in silver single crystals, Journal of Applied Physics 33 (11) (1962) 3149-3152.

[28] C. Chen, A. Hendrickson, Dislocation etch pits in silver, Journal of Applied Physics 42 (6) (1971) 2208-2215.

[29] R. Nelson, D. Mazey, R. Barnes, The thermal equilibrium shape and size of holes in solids, Philosophical Magazine 11 (109) (1965) 91-111.

[30] R. Klueh, W. Mullins, Periodic precipitation (Liesegang phenomenon) in solid silver-I. experimental, Acta Metallurgica 17 (1) (1969) 59-67.

[31] R. Klueh, W. Mullins, Periodic precipitation (Liesegang phenomenon) in solid silver-II. Modification of Wagner's mathematical analysis, Acta Metallurgica 17 (1) (1969) 69-76.

[32] C. Wagner, Mathematical analysis of the formation of periodic precipitations, Journal of Colloid Science 5 (1) (1950) 85-97. 